\title{
Necropolítica e governo Jair Bolsonaro: repercussões na seguridade social brasileira
}

\author{
Daniela Ribeiro Castilho ${ }^{1}$ \\ https://orcid.org/0000-0002-6976-7985
}

\author{
Esther Luíza de Souza Lemos² \\ http://orcid.org/0000-0002-7154-1475
}

${ }^{1}$ Universidade Federal do Pará (UFPA), Faculdade de Serviço Social, Programa de Pós-Graduação em Serviço Social, Belém- PA, Brasil

${ }^{2}$ Universidade Estadual do Oeste do Paraná (Unioeste), Curso de Serviço Social, Programa de Pós-Graduação em Serviço Social, Toledo-PR, Brasil

\section{Necropolítica e governo Jair Bolsonaro: repercussões na seguridade social brasileira}

Resumo: Este artigo busca problematizar o avanço do modelo ultraneoliberal presente no governo Bolsonaro e seus impactos na política de seguridade social brasileira, enquanto política pública e como tal, dever do Estado. O avanço das contrarreformas reacionárias destrói os sustentáculos essenciais da política de seguridade social: a saúde, previdência e assistência social. A metodologia escolhida consiste na pesquisa bibliográfica a partir de produções científicas publicadas em artigos e livros, como também, jornais e revistas sobre a temática. A agenda ultraneoliberal impõe uma perseguição sem precedentes aos direitos historicamente conquistados. Em tempos de pandemia pela Covid-19, as contradições da política de negação de direitos se evidenciam. O bolsonarismo tem implementado como política oficial a necropolítica, que advém de um domínio autoritário de definir quem deve morrer e quem merece viver, aprofundando ainda mais a barbárie social contra a classe trabalhadora. Palavras-chave: Seguridade Social. Necropolítica. Ultraneoliberal. Pandemia.

\section{Necropolitics and the Jair Bolsonaro government: repercussions on Brazilian social security}

Abstract: This article seeks to problematize the advancement of the ultraneoliberal model present in the Bolsonaro government and its impacts on the Brazilian social security policy, as a public policy and as such, the duty of the State. The advance of reactionary counter-reforms destroys the essential pillars of the social security policy: health, social security and social assistance. The chosen methodology consists of bibliographic research based on scientific productions published in articles and books, as well as newspapers and magazines on the subject. The ultraneoliberal agenda imposes an unprecedented pursuit of the rights historically won. In pandemic times for Covid-19, the contradictions of the denial of rights policy are evident. Bolsonarism has implemented necropolitics as an official policy, which comes from an authoritarian domain of defining who should die and who deserves to live, further deepening the social barbarism against the working class.

Keywords: Social Security. Necropolitics. Ultraneoliberal. Pandemic. 


\section{Introdução}

O presente artigo problematiza as medidas tomadas pelo governo Jair Bolsonaro no Brasil no âmbito da política de Seguridade Social, particularmente na atenção à política de previdência social, saúde e assistência social. Seus primeiros vinte e seis meses de governo revelam o desmonte significativo dos poucos direitos conquistados pela classe trabalhadora brasileira.

Estamos vivendo tempos sombrios e áridos, em que a crise do capital e seu profundo ataque contra o trabalho e os direitos da classe trabalhadora não parecem ter precedentes. Este breve ensaio abordará inicialmente a análise das condições objetivas e subjetivas que propiciaram a ascensão de Jair Bolsonaro à Presidência da República do Brasil num contexto de avanço da extrema direita no mundo. Os desvalores vividos pela sociedade evidenciam as consequências do crescimento do protofascismo, do ódio de classe e dos crimes de xenofobia, lgbtfobia e racismo. As mortes e chacinas destes "ninguéns, que custam menos do que a bala que os mata" (GALEANO, 1995) têm sido naturalizadas de forma inacreditável.

É emblemático lembrar o assassinato no dia 18 de maio de 2020, do adolescente negro João Pedro Mattos, de 14 anos, atingido por um tiro de fuzil numa operação conjunta entre as polícias Federal e Civil no morro do Salgueiro, em São Gonçalo, na Região Metropolitana do Rio de Janeiro, como também, do menino Miguel Otávio Santana da Silva, filho único da empregada doméstica Mirtes Renata que caiu de uma altura de 35 metros do prédio da patroa, na cidade do Recife, após Sarí Corte Real, consentir que a criança, de cinco anos, entrasse no elevador sozinha (COELHO; JÚNIOR; PEIXOTO, 2020). Em ambos os casos o que impera no Brasil é o racismo estrutural que sela o futuro da população negra e periférica e explicita o projeto macabro e genocida, travestido de fatalidade, do capital.

De acordo com matéria publicada no site do G1 em 2019, o Estado do Rio de Janeiro, segundo o Instituto de Segurança Pública (ISP) registrou um aumento de 23\% de mortes por intervenções policiais no primeiro semestre de 2019 (ESTADO..., 2020). Em São Paulo, não se pode esquecer o descaso do governo de João Dória com relação à tragédia ocorrida em 01/12/2019 na favela de Paraisópolis quando 09 (nove) jovens, que participavam de um baile funk, morreram pisoteados em uma perseguição policial (CERÂNTULA; TRALLI; VIEIRA, 2019).

Vive-se neste momento no Brasil uma forte recessão econômica e um contexto muito peculiar de pandemia do novo Coronavírus, que expressa, na verdade, a profunda desigualdade social existente no mundo, e mais especificamente, no Brasil. Esta realidade, em sua maior potência, indica que apesar da contaminação parecer atacar a todos/as, de fato, nada têm de democrática, na medida em que, é a classe trabalhadora que vivencia as piores condições de vida, trabalho, moradia, alimentação, saneamento, acesso à saúde e negação de outros direitos sociais. Esta, portanto, tem menores condições de resistir, seja do ponto de vista de sua imunidade biológica ou de sua imunidade social. Numa conta matemática simples, os donos do poder, mais uma vez decidem quem vive e quem morre, como seres descartáveis.

O projeto político do bolsonarismo, de um estado totalitário, naturaliza o uso da força e da violência, instigando a problematização, em particular, no campo dos direitos sociais: qual a particularidade da luta de classes neste tempo histórico na realidade brasileira? Quais tendências se evidenciam no trato da política de seguridade social, em especial, nas políticas de previdência social, saúde e assistência social? Quais as tarefas históricas colocadas à classe trabalhadora no governo ultradireita de Jair Bolsonaro? Estas e outras questões têm provocado aqueles/as que, na defesa do Estado Democrático de Direito, têm trabalhado, pesquisado e militado nos mais diferentes espaços públicos e movimentos sociais.

O contexto econômico, político, cultural e social da realidade brasileira expõe o avanço e endurecimento do ultraneoliberalismo, em todas as esferas da existência humana, em sua face hiperautoritária, com expressões ultraconservadoras e protofascistas (DARDOT; LAVAL, 2016). A análise e elaboração aqui apresentadas estão em fase germinal, muito em virtude da velocidade e dinamicidade dos acontecimentos e elementos presentes na realidade, o que nos coloca um desafio e um cuidado maior no processo de desocultamento do real na contemporaneidade.

O compromisso ético-político da pesquisa e da universidade nesta quadra histórica tem sido, além de desvelar a realidade social, denunciar e socializar o conhecimento transformando a "arma da crítica" em força viva com potencial mobilizador e de construção de nova consciência. Este é objetivo e o sentido das reflexões aqui presentes. 


\section{O bolsonarismo e a expressão aguda da necropolítica}

No Brasil, a aceleração das políticas ultraconservadoras e ultraneoliberais encontraram, no governo de Jair Bolsonaro, um solo fértil para crescer e se alastrar sem medidas. Os sucessivos cortes e privatização na saúde pública, na previdência e assistência social fazem a diferença nas ações do Estado para conter ou não a pandemia em terras brasileiras. De acordo com dados divulgados pelo Instituto Brasileiro de Geografia e Estatística (IBGE) em março de 2020, os/as trabalhadores/as informais representavam 40,6\% do total de trabalhadores/as ocupados/as no País no trimestre móvel até fevereiro deste ano, o que equivale a 38,081 milhões de pessoas (BÔAS, 2020). O alto índice de massas trabalhadoras na informalidade, cerca de 40 milhões, indica que estas estarão abandonadas pelo Estado, pois serão os indicadores das desigualdades sociais e de exploração que dirão quais os corpos terão mais condições de reagir e sobreviver.

Algumas orientações de enfrentamento à pandemia, como "ficar em casa"; "evitar aglomerações" e "lavar as mãos", não faz parte da realidade de milhares de trabalhadores/as informais no Brasil. Uma parcela considerável da população brasileira não tem acesso à água potável; à moradia; ao automóvel particular, algum bem de consumo ou tipo de direito trabalhista e previdenciário que possibilite a mínima proteção neste momento em que o medo e o pânico parecem tomar conta de todos/as. Para uma parcela significativa da classe trabalhadora, ou sai de casa ou não se tem o que comer, nem pagar as contas; ou se pega o trem lotado ou não se ganha o pão.

Segundo pesquisa do IBGE divulgada em maio de 2020 houve um aumento considerável da desigualdade social em 2019. Os dados levantados pelo módulo Rendimento de Todas as Fontes, da Pesquisa Nacional por Amostra de Domicílios (PNAD) demonstra que em 2019 o rendimento médio mensal real do trabalho da parcela da população com rendimentos mais elevados, $1 \%$, era de $\mathrm{R} \$ 28.659,00$, bem diferente dos $50 \%$ da população com menor rendimento que recebiam somente $\mathrm{R} \$ 850,00$. Ou seja, mais de 33 vezes menos que o valor recebido pelo $1 \%$ mencionado (RIOS, 2020).

A pandemia evidenciou objetivamente a contradição incontornável da sociabilidade capitalista. Segundo Safatle, Silva Júnior e Dunker (2018, p. 10), "uma época histórica pode ser descrita a partir das patologias que ela faz circular e das patologias que ela invalida". Isso nos permite refletir sobre o tempo histórico presente, ao produzir epidemias e pandemias que provocam sistematicamente a morte de milhares de pessoas e ao mesmo tempo refletem o percurso político-econômico trilhado pelo capitalismo em sua fase contemporânea. O governo brasileiro optou conscientemente por uma política de morte, ou nos termos de Mbembe (2016), pela necropolítica, como política oficial do Estado. Para o referido autor, tal conceito opera com o extermínio de populações, sendo a soberania,

a expressão máxima, do poder e da capacidade de ditar quem pode viver e quem deve morrer. Por isso, matar ou deixar viver constituem os limites da soberania, seus atributos fundamentais. Exercitar a soberania é exercer controle sobre a mortalidade e definir a vida como a implantação e manifestação de poder. (MBEMBE, 2016, p. 123).

A necropolítica de Bolsonaro utiliza o Estado para subjugar qualquer possibilidade de vida ao poder da morte. Não se trata de ações desconexas, eventuais, pontuais ou excepcionais, trata-se, sim, de ações políticas que se transformaram em regra e não em exceção, que define quem importa e quem não tem importância, quem é essencial e quem é descartável.

A opção pela violência e morte neste governo é incorporada aos processos institucionais, numa espécie de industrialização da morte, como a que estamos presenciando neste contexto da pandemia. A burocratização, por exemplo, para acesso ao auxílio emergencial, em tempos de Coronavírus, proposto pelo governo é um exemplo explícito de como estes mecanismos institucionais acabam contribuindo para aumentar cada vez mais os índices de desigualdade social no País por meio de uma política de morte, arquitetada nos porões do Planalto.

Ao mesmo tempo em que vivenciamos a dramaticidade da pandemia do Coronavírus e jogados/as à sorte pela falta de uma política sanitária e econômica que enfrente de forma fundamentada, planejada, responsável e célere o cenário de terra arrasada em que nos encontramos, vemos estarrecidos/as o avanço sem precedentes da política de austeridade fiscal levada a cabo pelo Ministro da Economia, Sr. Paulo Guedes, que tem como 
único horizonte o Estado brasileiro todo privatizado. Ao mesmo tempo, no guarda-chuva da lei de calamidade pública, aumentam as denúncias de fraudes nas compras públicas.

A pressão para que o governo aumente os investimentos públicos diante do contexto de calamidade pública tem sido a tônica das disputas acirradas entre alguns setores da burguesia nacional, mas há um obstáculo intransponível defendido pelo governo Bolsonaro que é a Emenda Constitucional (EC) $\mathrm{n}^{\circ}$ 95. Esta limita os gastos federais por 20 anos e só podem ser ajustados de acordo com a inflação acumulada conforme o Índice Nacional de Preços ao Consumidor Amplo (IPCA) acumulada nos últimos 12 meses (BRASIL, 2016).

A EC 95 na prática congela o orçamento, em particular, da seguridade social, prejudicando de fato os que se encontram em condições agravadas de vulnerabilidade social, impondo ainda mais para a classe trabalhadora um modelo de proteção social bem abaixo dos padrões mínimos de sobrevivência.

A aprovação pelo Congresso e Senado do congelamento de salários até dezembro de 2021 dos/as servidores/as públicos/as municipais, estaduais e federais, evidencia quem de fato vai pagar a conta desta crise sanitária e econômica produzida pelo capital: os/as trabalhadores/as.

Não há justificativa plausível para agudizar ainda mais as péssimas condições de vida e trabalho dos/as servidores/as públicos. O mesmo Estado brasileiro tem todas as condições para assumir os custos inerentes ao contexto de calamidade pública. De acordo com o site UOL, em março de 2020, por conta da crise agravada pela pandemia, o Banco Central disponibilizou aos bancos brasileiros um pacote de $\mathrm{R} \$ 1,216$ trilhão, ou seja, o equivalente a 16,7\% do Produto Interno Bruto (PIB) (CASTRO; RODRIGUES, 2020).

Ficam evidentes as escolhas feitas pelos arautos de plantão, o que nos coloca o dever de pensar na necessidade urgente de construir formas alternativas a este determinado modo de vida, opressor e exterminador de corpos, subjetividades e sentidos.

A naturalização e legitimação da violência, insegurança econômica, desmonte de direitos, ataque às experiências democráticas, extermínio da população que vive na periferia, passa a ser encarada como a legalidade que deve ser aceita pela classe trabalhadora. O neoliberalismo, e sua expressão jurídica, o estado de exceção, torna-se um novo paradigma para explicar governos autoritários que mantém a legalidade constitucional atacando e desconsiderando esta mesma ordem legal (VALIM, 2017).

Vivencia-se na contemporaneidade uma retirada quase total dos direitos historicamente conquistados e a centralização e fortalecimento do poder nas mãos do executivo, que não tem titubeado em lançar mão de um conjunto de medidas de cariz totalitário sob o pretexto de garantir a proteção de seu governo. Este paradigma transforma uma situação de emergência em regra, dando uma roupagem de legalidade jurídica a um conjunto de práticas não consideradas no regramento constitucional.

O governo Bolsonaro é marcado por uma direção política que atenta contra a própria sobrevivência da classe trabalhadora. Sua escolha pela necropolítica impõe um extermínio a todos/as aqueles/as que ameacem o grande capital, como é o caso das ações orquestradas contra os povos indígenas, ribeirinhos e quilombolas; contra a Amazônia e seu desmatamento criminoso; na liberação de centenas de agrotóxicos; no pacote anticrime; na contrarreforma da previdência social; na garantia de armamento aos grandes proprietários de terra; nas reduções orçamentárias das políticas sociais; nos sucessivos cortes nas universidades e na cultura, e, portanto, no descrédito com relação à ciência e à cultura, como campos de elevação da consciência.

Em nenhuma das propostas existe algo que se volte à proteção da vida da população que vive em condições de fome e miséria. Não há nada que promova e preserve a vida, ao contrário, todas as ações de seu governo vão na direção de viabilizar a morte, por meio, do enxugamento total do Estado brasileiro, transformando-o por completo em um Estado de contenção social ou penal ${ }^{1}$, que aplica uma política punitiva potencialmente agressiva contra a classe trabalhadora, em especial, contra negros/as; população LGBTQI+ e mulheres.

Assim, o governo Bolsonaro acaba por ratificar e aprovar suas necropráticas absolutamente discriminatórias, racistas e lgbtfóbicas que sempre estiveram presentes desde o Brasil colonial, mas que atualmente têm a anuência e aprovação de uma parte considerável da população que acaba sendo envolvida numa trama que tece a teia de sua morte, sem perceber que está sendo aniquilada.

Do ponto de vista subjetivo, o governo de Bolsonaro representa ainda uma reação reacionária, patriarcal, misógina, racista e lgbtfóbica aos novos parâmetros de direitos conquistados por populações que historicamente tiveram seus direitos invisibilizados e que colocaram as normativas tradicionais de comportamentos em cheque. A figura do então presidente encarna, de forma patética, a lacuna deixada pela decadência das figuras paternas 
que ao longo do tempo foram se limitando a modelos sempre binários e que começam a ser questionadas pela aparição e reconhecimento de outras formas não normativas na sociedade capitalista (DUNKER, 2019).

A ascensão do que representa Bolsonaro, ou seja, o mito-pai-falo é uma retomada, por meio da violência e do silêncio, do aniquilamento de todos/as os/as outros/as que representam uma ameaça à ordem patriarcal. É a reconquista do espaço perdido que visa legitimar as perversidades contra esses/as e recolocar o homem, branco e heterossexual, como representação dominante de nosso universo simbólico, na medida em que, o enfraquecimento da ordem patriarcal impôs uma nova forma de sociabilidade com as alteridades, e instituiu novos traços de produção de subjetividade, não somente àquelas ligadas às novas legislações protetivas e garantidoras de direitos, mas também, àquelas que dizem das maneiras e dos jeitos com que lidamos com o pertencimento, corpos, sexo, identidade e reconhecimento na sociedade (DUNKER, 2019).

Freud (1996) também nos ajuda a compreender, por meio de sua teoria narcisista, o bolsonarismo, como expressão do super-homem, líder e salvador que, ao mesmo tempo em que, cultiva essa ideia, torna-se uma pessoa capaz de falar da forma e do conteúdo muito próximo da multidão. Isso produz, em alguma medida, a abdicação dos egos individuais de seu séquito em direção ao ego materializado pelo mito.

Aqui Adorno (2006) nos dá pistas interessantes de como do ponto de vista simbólico isto está representado no coletivo de seus adeptos e fiéis escudeiros/as, quando diz que esta representação simbólica do mito se apresenta como "formação imaginária de uma figura paterna onipotente e violenta, altamente capaz de transcender o pai real e, com isso, crescer até se tornar um ego coletivo" (ADORNO, 2006, p. 172).

Esta realidade e a simbologia que ela carrega, tem em alguma medida se constituído como elemento favorável, para as transformações e destruições no campo dos direitos sociais pelo governo Bolsonaro, apesar das pesquisas de opinião já indicarem um nível de desgaste em sua própria base de eleitores/as². Isso, no entanto, não foi capaz de impedir a aprovação da "reforma" da previdência social que deixará à mingua milhões de trabalhadores/as.

Como já antecipava Boschetti (2016, p. 1): "vivemos um verdadeiro tornado antissocial" que tem na aprovação das alterações da previdência social, o desmonte da ideia de seguridade social, como um sistema integrado de proteção social, que inclui a saúde e a assistência social. Nesse contexto, abordaremos a seguir a intensidade dos ataques sofridos no campo da seguridade social a partir do governo Bolsonaro.

\section{A realidade da (des)proteção social na Seguridade Social brasileira}

Partindo da análise de que a política econômica é também política social, a disputa do fundo público pelo capital rentista tem se evidenciado de forma cruel e genocida para a classe trabalhadora. Os poucos direitos conquistados no âmbito da proteção social devida pelo Estado por meio da política de Seguridade Social têm sido duramente atacados e destruídos. A contrarreforma da Previdência Social foi uma das prioridades deste desgoverno, simultaneamente agindo com o contingenciamento e corte de recursos públicos antes destinados às ações governamentais. A centralidade no desmonte da previdência social pública, não significou, em nenhum momento, que as demais políticas de seguridade social estivessem fora do alvo do governo Bolsonaro, ao contrário, foram uma a uma sendo desmontadas e refuncionalizadas sob outra ótica.

O sistema de seguridade social brasileiro como conhecemos atualmente só foi possível a partir da Constituição Federal de 1988 que possibilitou uma reorganização e reestruturação com concepções e orientações inovadoras que tinham como horizonte a instituição de um amplo sistema de proteção social. No entanto, tais inovações não se materializaram por completo, ficando inconclusa e se configurando por um sistema híbrido que combina direitos vinculados e advindos do trabalho, como é o caso da previdência social; com direitos do tipo universal, como a saúde e com função universalizante na política de assistência social (BOSCHETTI, 2009). O que se evidenciou nos últimos 30 anos foi a não implementação da Seguridade Social brasileira,

aquelas diretrizes constitucionais, como universalidade na cobertura, uniformidade e equivalência dos benefícios, seletividade e distributividade nos benefícios, irredutibilidade do valor dos benefícios, equidade no custeio, diversidade do financiamento e caráter democrático e descentralizado da administração (C.F, artigo 194), não foram totalmente materializadas e outras orientaram as políticas sociais de forma bastante diferenciada. (BOSCHETTI, 2009, p. 330). 
A onda neoliberal que assolou o Brasil, logo após a promulgação da Constituição Federal de 1988, impôs um ajuste fiscal brutal que impactou sobremaneira nos direitos até então adquiridos pelos/as trabalhadores/ as, causando um horrendo panorama de declínio social por meio do crescimento e intensificação da pobreza e extrema pobreza (SOARES, 2000). Assim, a seguridade social brasileira, objeto de sucessivos ataques por parte dos setores mais conservadores da burguesia nacional e internacional, foi caminhando para o que Vianna (1998) denominou de americanização perversa, na medida em que, o modelo estatal foi se aprimorando cada vez mais numa espécie de atendimento de péssima qualidade voltado aos mais pobres. Mesmo assim, tem sido o Sistema Único de Saúde (SUS) e o Sistema Único de Assistência Social (SUAS), a salvação da proteção social brasileira no contexto da pandemia, juntamente com o acesso aos poucos direitos previdenciários.

Esta lógica, de uma seguridade social inconclusa somada e adensada a uma ideologia antiestado presente no governo de Bolsonaro esgarça e fragiliza ainda mais o que restou do sistema de proteção social. Em apenas vinte e seis meses de governo a destruição implementada pelo Estado, que constitucionalmente tem o dever de financiar e implementar políticas de proteção social, revela a agudeza do ultraneoliberalismo e genocídio perpetrado pelo Estado: a necropolítica, descrita acima. O investimento nas políticas setoriais que integram a seguridade social prevista constitucionalmente seria o contraponto de um Estado Social, fruto do pacto social da década de 1980 e de um padrão civilizatório para o País.

Apesar dos sucessivos cortes na política de Assistência social, lembremos aqui a Portaria no 2362/2019 publicada pelo então Ministro da Cidadania, Osmar Terra, que resultou no corte de cerca de $40 \%$ dos recursos federais e pôs em risco o pacto federativo e a continuidade dos serviços desta política (BRASIL, 2019), o governo Bolsonaro, em meio à pressão do Congresso, liberou um aporte extraordinário de $\mathrm{R} \$ 2,5$ bilhões para fortalecer as atividades do Sistema Único de Assistência Social (SUAS). O foco central desta medida foi possibilitar que municípios com maior ocorrência de Coronavírus tivessem condições de prover Benefícios Eventuais à população. A Medida Provisória no 953/20 previu ações de enfrentamento, no campo da saúde pública, ao Coronavírus no contexto do SUAS, atendendo tanto usuários/as cadastrados/as, quanto àqueles/ as que se encontram sem as mínimas condições de prover seus sustentos (BRASIL, 2020).

Essa ação, juntamente, com a aprovação do Auxílio Emergencial, pensada primeiramente pelo governo no valor de $\mathrm{R} \$ 200,00$ e, após pressão do parlamento, alterada para $\mathrm{R} \$ 600,00$ e $\mathrm{R} \$ 1.200,00$ (mães solteiras chefes de família) não tem sido suficiente para dar conta da crise sanitária e econômica vivenciada no País.

O contexto de agravamento das condições de vida pela pandemia num país que tem uma taxa informalidade de 39,9\% (36,8 milhões) da população ocupada (INSTITUTO BRASILEIRO DE GEOGRAFIA E ESTATÍSTICA, 2020) tem levado, inevitavelmente, uma parcela considerável da população brasileira a tornar-se usuária do SUAS $^{3}$. A estimativa do governo é de que até 70 milhões de pessoas possam receber o Auxílio Emergencial, dado que demonstra a dimensão da tragédia vivenciada no Brasil. Esse quantitativo equivale a quase o dobro da população do Canadá e bem mais que a totalidade da população da Argentina.

As medidas governamentais ainda se encontram aquém das que seriam necessárias para mitigar os impactos econômicos. O Auxílio Emergencial tem se tornado um calvário sem fim para a classe trabalhadora que se vê obrigada a enfrentar filas quilométricas na Receita Federal e nas agências da Caixa Econômica para garantir o acesso ao benefício. Parece ser a punição de um governo eugenista e perverso que, conscientemente, trabalha para prover as piores condições para as massas de trabalhadoras/es em tempos obscuros.

As medidas na área da saúde também não têm sido diferentes. Vemos cotidianamente nos noticiários, nas mídias sociais, no interior das nossas famílias e no trabalho profissional o resultado de anos de sucateamento da saúde pública num País de desigualdade social abissal. O desmonte do SUS vem de longa data, mas se intensificou no governo de Bolsonaro, a partir da aprovação no governo Temer da EC 95, que vem afetando consideravelmente o financiamento do Sistema. O SUS nunca teve o financiamento necessário, ao contrário, sempre foi subfinanciado, e com a aprovação da emenda do teto dos gastos, o governo explicitamente impôs um processo acelerado de desfinanciamento ${ }^{4}$.

Um dos efeitos perversos das políticas econômicas de austeridade fiscal do neoliberalismo, no caso do Brasil, é que nunca o Estado foi tão necessário como agora. Políticas de privatização do Estado, por meio do desmonte, destruição e mercantilização das políticas de seguridade social; terceirizações irrestritas; contrarreformas trabalhista e previdenciária; desemprego em massa; crescimento da informalidade; aumento da violência estatal; degradação e demonização dos serviços e servidores/as públicos e sucateamento sistemático 
do SUS explicitaram um cenário de guerra e luta contra a fome e a morte em tempos de confinamento físico imposto pela pandemia.

A disputa histórica entre os dois projetos, o da Reforma Sanitária e o Privatista, para a área da saúde tem favorecido este último, no qual o elemento central é a produção da doença como fonte de lucro e, portanto, nicho de mercado. $\mathrm{O}$ avanço da tendência ultraneoliberal, a partir do governo Temer tem acirrado ainda mais as disputas políticas por dentro do SUS destes dois projetos e em tempos de pandemia, a histórica redução de verba pública produziu um cenário de restrições e limites para o acesso universal ao sistema.

Os tempos atuais explicitam o colapso do sistema de saúde pública brasileiro e o estado mínimo se faz sentir nas dores máximas da população mais periférica que enfrenta grandes filas, faltas de leitos, de profissionais da saúde, de respiradores, de remédios e sobram atendimentos precários que na maioria das vezes determinam a vida ou a morte de quem precisa do SUS para se tratar dos sintomas do coronavírus, já que o sistema público tem sido a única possibilidade de a classe trabalhadora ter acesso à saúde, no entanto, o que se tem presenciado é a hegemonia da lógica mercantilista e gerencialista para a saúde pública (BRAVO et al., 2018).

O governo Bolsonaro manteve a sangria contra o SUS, inclusive intensificando-a, sendo que uma de suas primeiras ações foi a destruição do Programa Mais Médicos, ainda que pesem críticas ao programa. Com suas limitações, atendia nada menos que 700 municípios, chegando a locais longínquos e de difícil acesso, em particular, no atendimento aos indígenas e populações tradicionais ${ }^{5}$.

A previdência social continuou a ser atacada pelo bolsonarismo. As sistemáticas crises do capital tiveram como respostas em todos os governos passados, mudanças nas legislações trabalhistas e previdenciárias que foram se transformando paulatinamente em "novos nichos de mercado" e, assim, puderam ingressar nos processos de valorização do valor que repousam unicamente na produção incessante das necessidades do capital.

Nesse sentido, para que os direitos sociais se tornem mercantilizados é preciso que, em alguma medida, sejam terceirizados ou privatizados, para que assim possam ser acessados via mercado. Há, dessa forma, uma conformação da lógica gerencialista por dentro do Estado, que busca um encolhimento dos investimentos estatais em políticas públicas e a captura do fundo público, como também, a disseminação ideológica de desresponsabilização e desregulamentação estatal de diversos equipamentos e áreas controladas pelo Estado (LARA, 2018).

Isso foi vivenciado na contrarreforma da Previdência Social, encaminhada pelo executivo e aprovada em outubro de 2019 pelo Parlamento. O grande e falacioso debate da necessidade de se fazer uma reforma baseava-se em três justificativas, as mesmas de outros movimentos anteriores de restrição de direitos no âmbito da previdência social 6 .

Estes discursos falaciosos foram à base da contrarreforma da previdência social, sendo aprovada e assim, possibilitam com maior liberdade a apropriação pelo capital financeiro dos recursos do orçamento público, como também, a orientação e direção das políticas sociais dos países periféricos. Os custos da contrarreforma serão pagos pela classe trabalhadora, já que uma das maiores mudanças se refere ao tempo e idade mínima para se aposentar, que passam a ser requisitos obrigatórios.

Os cálculos demonstram que os/as trabalhadores/as terão de trabalhar muito mais para terem acesso a 100\% de aposentadoria. Para Boschetti (2018), o capitalismo, por meio do Estado burguês,

[...] ao suprimir ou diminuir os direitos sociais de saúde e previdência, obrigam a classe trabalhadora a despender parte de seu salário com a compra de bens e serviços no mercado, operando a transformação dos direitos em mercadorias; [...] ao reduzir os direitos de aposentadoria, seguro-desemprego, segurosaúde, reduzem a participação do Estado Social na reconstituição física da força de trabalho e obrigam a classe trabalhadora a oferecê-la no mercado a qualquer custo e em qualquer condição, 'livres como os pássaros' (BOSCHETTI, 2018, p. 159).

Na prática a contrarreforma da previdência social aumenta o nível de exploração e ameaça objetivamente a vida da classe trabalhadora, pois significa um aumento injusto no tempo e nos percentuais de contribuição o que acaba por restringir o tempo e o valor com que cada trabalhador/a poderá usufruir do benefício provocando um adensamento substancial da desigualdade social no Brasil. 


\section{Considerações Finais}

A necropolítica se impôs com nitidez no governo Bolsonaro. Em meio à grave crise econômica e à pandemia viral, o governo brasileiro continua com sua política de morte contra a classe trabalhadora. Em análise feita pela Agência Pública, com base nos boletins epidemiológicos do Ministério da Saúde, o Coronavírus atinge em maior quantidade negras/os e periféricas/os. Os dados indicam que há 1 (uma) morte para três pessoas negras hospitalizadas pela Covid-19. Entre pessoas brancas essa proporção cai para 1 (uma) morte em cada 4,4 hospitalizações. Ainda segundo a Agência Pública, em São Paulo, cidade com maior número de casos no Brasil, dos dez bairros com maior quantitativo absoluto de óbitos causados pelo Coronavírus, oito têm mais negros que a média de São Paulo (MUNIZ; FONSECA; PINA, 2020). Esses dados demonstram o tamanho da desigualdade social e racial que existe no Brasil, na medida em que, é a população negra da periferia que vive em piores condições de vida e mais tem morrido no País.

Além de viverem neste tempo histórico, um tempo violentamente inseguro, com a perda real de seus trabalhos temporários e informais, por conta do necessário distanciamento social, suas famílias vivem também o profundo descaso e descomprometimento deste governo.

A expropriação dos direitos sociais, fruto das contrarreformas sistemáticas no campo trabalhista e nas políticas setoriais, em particular, da seguridade social, além de impor modos de vida cada vez mais degradantes à classe trabalhadora, ainda à condena a aceitar condicionalidades e regulamentos, na maioria das vezes, humilhantes (BOSCHETTI, 2018).

Mais do que nunca o sistema previdenciário, a política de assistência social e saúde precisam garantir, com recursos financeiros, recursos físicos, equipes de referência, equipamentos de proteção individuas e serviços de qualidade, proteção e efetivação dos direitos sociais. Nesse sentido, é urgente e necessário o financiamento estatal, manutenção e ampliação da rede de proteção social em todos os municípios do País.

As políticas de assistência social, saúde e previdência social são essenciais e fazem a diferença na proteção e acolhimento de pessoas em situação de rua, idosos, mulheres, crianças e adolescentes. Hoje mais do que nunca se tornou imperativo defender o SUAS e o SUS, como forma de minimizar os impactos econômicos e garantir a vida da população brasileira.

Necessário ainda, continuar a defender a previdência pública e a ampliação de cobertura para todos/as que vivem riscos por conta do trabalho e o espectro do desemprego. Aqui defendemos a aprovação da política de Renda Básica na garantia do direito à renda. Neste enfrentamento é fundamental a defesa da auditoria da dívida pública que, para nós é arbitrária e espúria, e que acaba criando mecanismos que incentivam a corrupção e alimentam o capital financeiro.

É fundamental acumular forças entre os movimentos sociais e partidos de esquerda na construção de um programa mínimo que possibilite a reorganização da classe trabalhadora, como também provoque nesta nova consciência e resistência para a defesa de seus direitos historicamente conquistados com muitas lutas, sonhos e sangue dos/as que nos antecederam. A construção de outro projeto de vida e de sociedade é possível e pode permear os nossos horizontes de esperança, pois a lição já sabemos de cor. Um projeto construído com o acúmulo das experiências feitas pela classe trabalhadora é urgente e a luta pela manutenção de nossas conquistas, como o SUAS, o SUS e a previdência social pública e estatal fazem parte desta estratégia de resistência e sobrevivência. Como nos lembra José Saramago (2005) "a única maneira de liquidar o dragão é cortar-lhe a cabeça, aparar-lhe as unhas não serve de nada". A vida vale mais que o lucro! Vidas negras importam!

\section{Referências}

ADORNO, T. W. A teoria freudiana e o padrão da propaganda fascista. Revista Margem Esquerda: Ensaios Marxistas, n. 7, p. 164190, 2006.

BÔAS, B. V. IBGE: País tinha 38,08 milhões na informalidade até fevereiro, mostra IBGE. Valor, Rio de Janeiro, 31 mar. 2020. Disponível em: https://valor.globo.com/brasil/noticia/2020/03/31/ibge-pais-tinha-3808-milhoes-na-informalidade-ate-fevereiro.ghtml. Acesso em: 5 jun. 2020. 
BOSCHETTI, I. S. A política de Seguridade Social no Brasil. In: Serviço Social: direitos sociais e competências profissionais. Brasília: CFESS/ ABEPSS/ CEAD, 2009. p. 323-338.

BOSCHETTI, I. S. América Latina, política social e pobreza: "novo” modelo de desenvolvimento? In: SALVADOR, E., Behring, E., Boschetti, I. S., Granemann, S. (org.). Financeirização, fundo público e política social. São Paulo: Cortez, 2012. p. 31-58.

BOSCHETTI, I. S. Essa proposta é um verdadeiro tornado antissocial'. Escola Politécnica de Saúde Joaquim Venâncio, Rio de Janeiro, 8 dez. 2016. Disponível em: http://www.epsjv.fiocruz.br/noticias/entrevista/essa-proposta-e-um-verdadeiro-tornado-antissocial. Acesso em: 14 maio 2020.

BOSCHETTI, I. Expropriação de direitos e reprodução da força de trabalho In: Expropriação e direitos no capitalismo / Ivanete Boschetti (Org.) São Paulo: Cortez, 2018. P. 131-166.

BRASIL. [Constituição 1988]. Emenda constitucional n 95, de 15 de dezembro de 2016. Altera o Ato das Disposições Constitucionais Transitórias, para instituir o Novo Regime Fiscal, e dá outras providências. Brasília, DF: Presidência da República, [2016]. Disponível em: http://www.planalto.gov.br/ccivil_03/constituicao/emendas/emc/emc95.htm. Acesso em: 5 jun. 2020.

BRASIL. Medida provisória n. ${ }^{\circ}$ 953, de 2020. Câmara dos deputados, Brasília, DF, 17 abr. 2020. Disponível em: https://www.camara. leg.br/proposicoesWeb/prop_mostrarintegra;jsessionid=5D6F440A5E9AC4568D28BF316B5EB517.proposicoesWebExterno1?codt eor=1887880\&filename=Avulso+-MPV+953/2020. Acesso em: 5 jun. 2020.

BRASIL. Ministério da Cidadania. Portaria $n^{\circ}$ 2.362, de 20 de dezembro de 2019. Estabelece procedimentos a serem adotados no âmbito do Sistema Único de Assistência Social decorrentes do monitoramento da execução financeira e orçamentária realizada pelo Fundo Nacional de Assistência Social para promover a equalização do cofinanciamento federal do Sistema Único de Assistência Social à Lei de Diretrizes Orçamentárias e à Lei Orçamentária Anual. Diário Oficial da União, Brasília, DF, 20 dez. 2019. Disponível em: https://www.in.gov.br/web/dou/-/portaria-n-2.362-de-20-de-dezembro-de-2019-234966986. Acesso em: 5 jun. 2020.

BRAVO, M. I. S. et al. As contrarreformas na Política de Saúde do governo Temer. Argumentum, Vitória, v. 10, n. 1, p. 9-23, jan./ abr. 2018.

CASTRO, F. de; RODRIGUES, E. Com crise, BC já anunciou R\$ 1,2 trilhão em recursos para bancos. UOL Economia, São Paulo, 23 mar. 2020. Disponível em: https://economia.uol.com.br/noticias/estadao-conteudo/2020/03/23/com-crise-bc-ja-anunciou-r-12trilhao-em-recursos-para-bancos.htm?cmpid=copiaecola. Acesso em: 5 jun. 2020.

CERÂNTULA, R.; TRALLI, C.; VIEIRA, B. M. Nove pessoas morrem pisoteadas em tumulto após ação da Polícia Militar durante baile funk em Paraisópolis, em SP. G1, São Paulo, 1 dez. 2019. Disponível em: https://g1.globo.com/sp/sao-paulo/noticia/2019/12/01/ perseguicao-e-tiroteio-em-baile-funk-em-paraisopolis-deixa-ao-menos-8-mortos-pisoteados-em-sp.ghtml. Acesso em: 16 dez. 2020. COELHO, H.; JÚNIOR, E.; PEIXOTO, G. Menino de 14 anos morre durante operação das polícias Federal e Civil no Complexo do Salgueiro, RJ. G1, São Paulo, 19 maio 2020. Disponível em: https://g1.globo.com/rj/rio-de-janeiro/noticia/2020/05/19/menino-de14-anos-e-baleado-durante-operacao-no-complexo-do-salgueiro-rj.ghtml. Acesso em: 16 dez. 2020.

DARDOT, P.; LAVAL, C. A Nova Razão do Mundo: Ensaio sobre a Sociedade Neoliberal. São Paulo: Boitempo, 2016.

DUNKER, C. Sob o Governo dos homens-falo. Le Monde diplomatique Brasil, São Paulo, 31 jul. 2019. Disponível em: https:// diplomatique.org.br/sob-o-governo-dos-homens-falo/. Acesso em: 14 abr. 2020.

ESTADO do Rio registra aumento de 23\% nos números de morte por intervenção policial em abril, diz ISP. G1, São Paulo, 20 maio 2020. Disponível em: https://g1.globo.com/rj/rio-de-janeiro/noticia/2019/05/20/rj-apresenta-aumento-de-23percent-nos-numeros-demorte-por-intervencao-policial-em-abril-diz-isp.ghtml. Acesso em: 5 jun. 2020.

FREUD, S. Sobre a Introdução do Conceito de Narcisismo. In: Edição Standard Brasileira das Obras Psicológicas Completas. Rio de Janeiro: Imago, 1996. v. 14.

GALEANO, E. O Livro dos Abraços. Porto Alegre: L\&PM, 1995.

governo-bolsonaro-nao-preve-novos-atendidos-pelo-bolsa-familia-em-2020.shtml disponível em: https://www1.folha.uol.com.br/ mercado/2019/12/. Acesso em: 20 jun de 2019.

INSTITUTO BRASILEIRO DE GEOGRAFIA E ESTATÍSTICA (IBGE). Pesquisa Nacional por Amostra de Domicílios - PNAD Contínua, Rio de Janeiro, out-dez. 2019. Disponível em: https://biblioteca.ibge.gov.br/visualizacao/periodicos/2421/pnact_2019_4tri. pdf. Acesso em: 19 jun. 2020.

INSTITUTO BRASILEIRO DE GEOGRAFIA E ESTATÍSTICA (IBGE). Pesquisa Nacional por Amostra de Domicílios - PNAD Contínua, Rio de Janeiro, 15 maio 2020. Disponível em: https://agenciadenoticias.ibge.gov.br/agencia-sala-de-imprensa/2013-agenciade-noticias/releases/27707-pnad-continua-trimestral-desocupacao-cresce-em-12-e-fica-estavel-em-15-ufs-no-1-trimestre-de-2020. Acesso em: 15 maio 2020.

LARA, R. Modernização Trabalhista: um país "livre para crescer”. In: INÁCIO, J. R. Trabalho, Saúde e Direitos Sociais. Bauru: Canal 6, 2018. 
MBEMBE, A. Necropolítica: biopoder, soberania, estado de exceção, política da morte". Revista Arte e Ensaios: Rio de Janeiro, n. 32, dez. 2016. Disponível em: https://revistas.ufrj.br/index.php/ae/article/ view/8993/7169?fbclid=IwAR2SAvwKICkMhUpLKAXp540_2BYPGYGhsEOvVA1NVdmgYcnbUt1Gv6fJt24. Acesso em: 05 jun. 2020. MUNIZ, B.; FONSECA, B.; PINA, R. Em duas semanas, número de negros mortos por coronavírus é cinco vezes maior no Brasil. Agência Pública, 6 maio 2020. Disponível em: https://apublica.org/2020/05/em-duas-semanas-numero-de-negros-mortos-porcoronavirus-e-cinco-vezes-maior-no-brasil/. Acesso em: 5 jun. 2020.

ORGANIZAÇÃO PANAMERICANA DE SAÚDE (OPAS); ORGANIZAÇÃO MUNDIAL DE SAÚDE (OMS). Folha Informativa: Programa Mais Médicos. OPAS/OMS, nov. 2018. Disponível em: https://www.paho.org/bra/index.php?option=com_content\&view= article\&id=5662:folha-informativa-programa-mais-medicos\&Itemid=347. Acesso em: 23 maio 2020.

REPROVAÇÃO ao governo Bolsonaro vai a 50\%, aponta XP/Ipespe; 57\% veem economia no caminho errado. InfoMoney, [S. 1.], 20 maio 2020. Disponível em: https://www.infomoney.com.br/politica/reprovacao-ao-governo-bolsonaro-vai-a-50-aponta-xp-ipespe-57veem-economia-no-caminho-errado/. Acesso em: 5 jun. 2020.

RIOS, R. Pesquisa do IBGE aponta crescimento na desigualdade social em 2019. Correio Braziliense, São Paulo, 6 maio 2020. Disponível em: https://www.correiobraziliense.com.br/app/noticia/brasil/2020/05/06/interna-brasil,851947/pesquisa-do-ibge-apontacrescimento-na-desigualdade-social-em-2019.shtml. Acesso em: 5 jun. 2020.

SAFATLE, W.; SILVA JÚNIOR, N. DA; DUNKER, C. (org.). Patologias do Social: Arqueologias do Sofrimento Psíquico. Belo Horizonte: Autêntica, 2018.

SARAMAGO, J. As intermitências da morte. São Paulo: Companhia das Letras, 2005.

SAÚDE perdeu R\$ 20 bilhões em 2019 por causa da EC 95/2016. Conselho Nacional de Saúde, [Brasília], 28 fev. 2020. Disponível em: http://conselho.saude.gov.br/ultimas-noticias-cns/1044-saude-perdeu-r-20-bilhoes-em-2019-por-causa-da-ec-95-2016. Acesso em: 5 jun. 2020.

SILVA, M. L. L. Contrarreforma da Previdência Social sob o comando do capital financeiro. Serviço Social e Sociedade, n. 131, p. 130-154, jan./abr. 2018.

SOARES, L. T. Os custos sociais do ajuste neoliberal na América Latina. São Paulo: Cortez, 2000.

VALIM, R. Estado de Exceção: A Forma Jurídica do Neoliberalismo. São Paulo: Contracorrente, 2017.

VIANNA, M. L. T. W. A Americanização (perversa) da seguridade social no Brasil: estratégias de bem-estar e políticas públicas. Rio de Janeiro: Revan/IUPERJ/UCAM, 1998.

WACQUANT, L. As prisões da miséria. Trad. André Telles. Rio de Janeiro: Jorge Zahar, 2001.

\section{Notas}

1 O conceito de Estado Penal é utilizado por Wacquant (2001, p. 10) para caracterizar o crescimento da repressão estatal sobre os setores mais pauperizados da sociedade, fruto dos efeitos perversos do trabalho restritivo e da contenção das políticas sociais. Segundo o autor, o Estado Penal é, em grande medida, a solução "às desordens pela desregulamentação da economia, pela dessocialização do trabalho assalariado e pela pauperização relativa e absoluta de amplos contingentes do proletariado urbano, aumentando os meios, a amplitude e a intensidade da intervenção do aparelho policial e judiciário".

2 A pesquisa de opinião realizada pela XP/Ipespe divulgada no dia 20 de maio de 2020 mostra que a avaliação do governo Jair Bolsonaro foi classificada por $50 \%$ como ruim/péssima, por 25\% como ótimo/bom e por 23\% regular (REPROVAÇÃO..., 2020).

3 Segundo a reportagem da Folha de São Paulo, de 02 de dezembro de 2019, o governo federal não incluiu para 2020, no orçamento do Bolsa Família novas famílias beneficiárias. A equipe do Ministro da Economia Paulo Guedes projetou o valor de R 29,5 bilhões para este ano, bem diferente de 2019 cujo valor foi de R \$ 32 bilhões. Isso significa que o sistema não conseguirá atender nesta crise que se adensa pela presença da pandemia, com alguma qualidade, o mínimo dos/as usuários/as da política de assistência social que explodirão como demandas para o Sistema. (https://www1.folha.uol.com.br/mercado/2019/12/governo-bolsonaro-naopreve-novos-atendidos-pelo-bolsa-familia-em-2020.shtml).

4 De acordo com o Conselho Nacional de Saúde (CNS) em matéria publicada em 28 de fevereiro de 2020, apenas no ano de 2019 a saúde pública perdeu em torno de 20 bilhões o que sinaliza efetivamente a desvinculação dos $15 \%$ do mínimo exigido da receita, no âmbito federal para a saúde (SAÚDE...; 2020).

5 Segundo a Organização Pan-Americana da Saúde e a Organização Mundial da Saúde (2018), o programa atendeu até o ano de 2018 mais de 60 milhões de brasileiros.

6 A primeira questão referia-se à saturação do regime de solidariedade intergeracional, que com o aumento da expectativa de vida da população brasileira, tornava-se impraticável gerando uma crise sem precedentes. Por isso a necessidade de transformá-lo em um regime de capitalização, ou seja, cada um por si, quebrando a ideia de que o/a trabalhador/a na ativa contribuiria para aqueles/ 
as que se encontram aposentados/as. A segunda responsabilizava os altos custos do trabalho e, por conta disso, o Estado como contrapartida se viu no dever de renunciar tributos em favor das empresas, diminuindo, dessa forma, a contribuição do capital e aumentando, por outro lado, a parcela dispendida pelos/as trabalhadores/as no custeio da previdência social. A terceira, e não menos importante, se referia ao aporte cada vez maior do Estado para a previdência pública o que teria ocasionado o crescimento da dívida pública, e com isso, o desequilíbrio das contas dos governos (SILVA, 2018).

\section{Daniela Ribeiro Castilho}

danicastilho@ufpa.br

Doutora em Serviço Social pela Universidade Federal do Rio de Janeiro (UFRJ)

Docente da Faculdade de Serviço Social (FASS) da Universidade Federal do Pará (UFPA)

\section{UFPA}

R. Augusto Corrêa, 01 - Guamá

Belém - PA- Brasil

CEP: 66075-110

\section{Esther Luíza de Souza Lemos}

estherlemos@gmail.com

Doutora em Serviço Social pela Universidade Federal do Rio de Janeiro (UFRJ)

Docente do Curso de Serviço Social da Universidade Estadual do Oeste do Paraná (Unioeste).

\section{UNIOESTE}

Rua da Faculdade, 645 Jardim La Salle

Toledo - PR- Brasil

CEP: 85903-000

\author{
Agradecimentos \\ Não se aplica. \\ Agência financiadora \\ Não se aplica. \\ Contribuições das autoras \\ $\mathrm{O}$ artigo foi elaborado em todas as partes pelas autores.
}

\author{
Aprovação por Comitê de Ética e consentimento para \\ participação \\ Não se aplica. \\ Consentimento para publicação \\ Consentimento das autoras. \\ Conflito de interesses \\ Não há conflito de interesses.
}

